\title{
The Study of the Behavior of Constrained Groove Pressed Magnesium Alloy after Heat Treatment
}

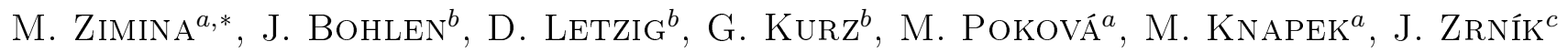 \\ AND M. CIESLAR ${ }^{a}$
}

${ }^{a}$ Charles University in Prague, Faculty of Mathematics and Physics, Ke Karlovu 5, 12116, Prague, Czech Republic

${ }^{b}$ Magnesium Innovation Centre (MagIC) Helmholz Zentrum Geesthacht, Max-Planck Str. 1, D21502 Geesthacht, Germany

${ }^{c}$ COMTES FHT a.s., Průmyslová 995, Dobřany 334 41, Czech Republic

\begin{abstract}
In this work twin-roll cast AZ31 magnesium strip of thickness $5.6 \mathrm{~mm}$ was subjected to the heat treatment and further constrained groove pressing. A comparison of the microstructure and microhardness of as-cast, constrained groove pressed and annealed material was carried out. The twin-roll cast strip exhibits an inhomogeneous structure which is replaced by a finer and uniform recrystallized one after aging at $450{ }^{\circ} \mathrm{C}$ for $10 \mathrm{~h}$. A significant increase of the microhardness was observed accompanied by a pronounce grain refinement. Nevertheless, the distribution of the grain size is unequal along the specimen width. Thermal stability of the deformed structure during subsequent annealing was investigated. It was shown that higher annealing temperatures result in a formation of a more uniform recrystallized structure and in a significant drop of microhardness down to the values obtained for as-cast alloy.
\end{abstract}

DOI: $10.12693 /$ APhysPolA.128.775

PACS: 62.20.F-, 62.20.Qp, 81.05.Bx, 81.05.Zx

\section{Introduction}

In the recent decade significant attention was paid to magnesium alloys and their applications in the automotive industry $[1,2]$. Methods of severe plastic deformation (SPD) in order to improve strength, ductility or corrosion resistance of magnesium alloys are under enormous interest [3-5]. The combination of energy saving continuous casting technique with further SPD treatment and annealing is very useful for the production of ultra-fine grained (UFG) sheet materials with unique properties. Twin-roll casting (TRC) of magnesium alloys is a continuous casting technique which allows the production of long thin strips of a good quality [6] and together with constrained groove pressing (CGP), which is wellestablished for aluminium alloys $[7,8]$, fine-grained sheets can be produced with almost no size reduction of the strip. As a result of hexagonal close-packed structure, magnesium alloys exhibit low ductility and high brittleness at room temperature [9]. Therefore, the application of CGP to magnesium alloys is limited because of the deformation mechanism characterized by the lack of active slip systems, which could be activated only at higher temperatures. In this paper the properties of TRC AZ31 strips improved by a high temperature CGP processing are reported. Their thermal stability and the uniformity of mechanical properties were studied and related to the observed microstructural changes.

* corresponding author; e-mail: m.zimina@seznam.cz

\section{Experimental procedure}

AZ31 magnesium alloy strips of $5.6 \mathrm{~mm}$ thickness produced using TRC technique with the chemical composition present in the Table were studied. Plates with dimensions $70 \times 55 \times 5.6 \mathrm{~mm}^{3}$ with the longest side parallel to the rolling direction (RD) were cut from the TRC strip for further CGP as is shown in Fig. 1a. In order to minimize the formation of cracks, plates were preheated at $450^{\circ} \mathrm{C}$ for $10 \mathrm{~min}$ in an air furnace before each of four CGP steps and immediately pressed with the asymmetric die [7]. The geometry of the die is shown in Fig. 1b. The die and the grooves were at room temperature and were oriented perpendicularly to the RD of the TRC material. After one CGP cycle plates were subjected to step-bystep annealing with $50^{\circ} \mathrm{C} / 50 \mathrm{~min}$ heating rate up to 250 , 300,350 , and $400^{\circ} \mathrm{C}$ and held for a one minute at given temperatures.

TABLE

Chemical composition of AZ31 magnesium alloy [wt.\%].

\begin{tabular}{c|c|c|c|c|c|c}
\hline \hline $\mathrm{Al}$ & $\mathrm{Zn}$ & $\mathrm{Mn}$ & $\mathrm{Ca}$ & $\mathrm{Cu}$ & $\mathrm{Fe}$ & $\mathrm{Mg}$ \\
\hline 3.45 & 0.98 & 0.28 & 0.002 & 0.002 & 0.004 & Balance
\end{tabular}

Moreover, one as-cast and one CGP specimens were aged at $450^{\circ} \mathrm{C}$ for $10 \mathrm{~h}$ in order to study the influence of long-term high temperature exposure.

The as-cast specimen and specimens after CGP were mechanically grinded, polished and etched by acetic picral solution and then subjected to light optical microscopy observations and Vickers microhardness testing with $100 \mathrm{~g}$ load. 

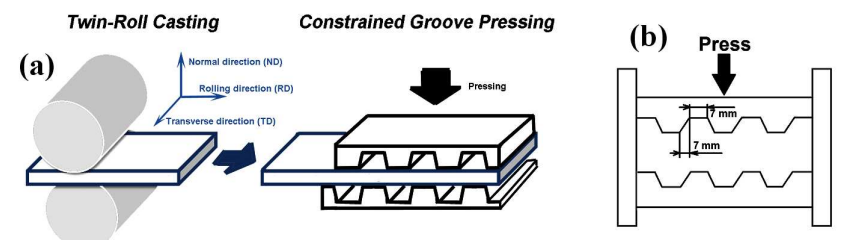

Fig. 1. a) Scheme of the twin-roll casting and following constrained groove pressing, b) scheme of the die used for constrained groove pressing.

The cross-sectional mapping of specimens was performed using a QNess A10+ microhardness tester and QPix Control software. The density of the indentation net was five indentations per square millimeter.

All micrographs were obtained using an Olympus GX51 light optical microscope on a longitudinal section in transverse direction (TD) of the samples.
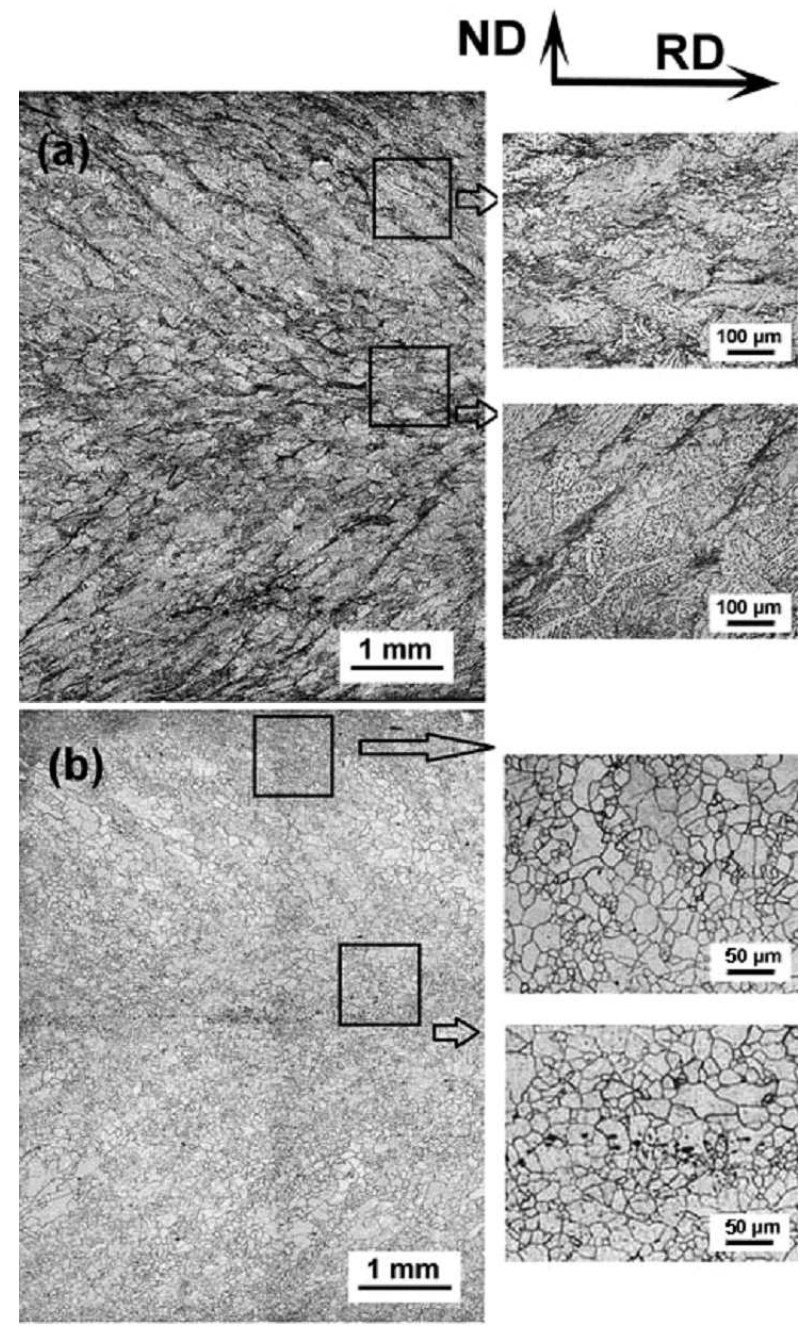

Fig. 2. Microstructure of the cross-sections of TRC AZ31 magnesium alloys: (a) as-cast and (b) aged at $450{ }^{\circ} \mathrm{C}$ for $10 \mathrm{~h}$. The surfaces of the TRC strip are at the top and bottom edge of the images and dark lines correspond to the grain boundaries.

\section{Results and discussion}

\subsection{Microstructure}

In recent studies $[6,10,11]$ it was shown that the TRC strip used in the present study was cast at optimal casting conditions with minimized inhomogeneity of the as-cast structure. The microstructure image of AZ31 magnesium alloy is shown in Fig. 2a. Due to the deformation imposed during TRC grain size in the surface layer is much smaller $(10-20 \mu \mathrm{m})$ than in the bulk of the sample $(200 \mu \mathrm{m})$. However, full recrystallization accompanied by a homogeneous distribution of fine grains (average size $\approx 50 \mu \mathrm{m}$ ) were observed after aging at $450^{\circ} \mathrm{C}$ for $10 \mathrm{~h}$ (Fig. 2b).



Fig. 3. Microstructure of as-deformed CGP AZ31 magnesium alloy: (a) cross-section of the plate, black line indicates position of the grooves; (b-d) significant areas indicated by white boxes in part (a).

One CGP cycle applied on the TRC semi-product after preheating at $450{ }^{\circ} \mathrm{C}$ for $10 \mathrm{~min}$ results in the formation of deformed structure which exhibits extensive heterogeneity along the RD (Fig. 3a). The grain size varies from tens to hundreds $\mu \mathrm{m}$ depending on the position along the RD. Three significant areas characterized by a different grain size located between two grooves are shown in Fig. 3b-d. Two similar zones with the grain size of about 15-20 $\mu \mathrm{m}$ are located in a distance of $7 \mathrm{~mm}$ representing the geometry of the die (Fig. 3b,d). Between them there is a transition zone which is characterized by grains of the size of about $50 \mu \mathrm{m}$ and a large fraction of deformation twins (Fig. 3c). As will be shown in the following section (3.2) the zones represent different extent of deformation imposed by different parts of the groove die.

In order to examine the resistance of the CGP material to the thermal loading specimens were annealed up to 250,350 , and $400^{\circ} \mathrm{C}$, as is described in previous section. The microstructure passes through substantial changes resulting in a more homogeneous distribution of the grain size, but the three distinctive areas can be still well distinguished at all annealing temperatures.

Figure 4 shows micrographs of specimens annealed at different temperatures. The microstructure after annealing at $250^{\circ} \mathrm{C}$ is almost the same as the one observed in the as-deformed material. 

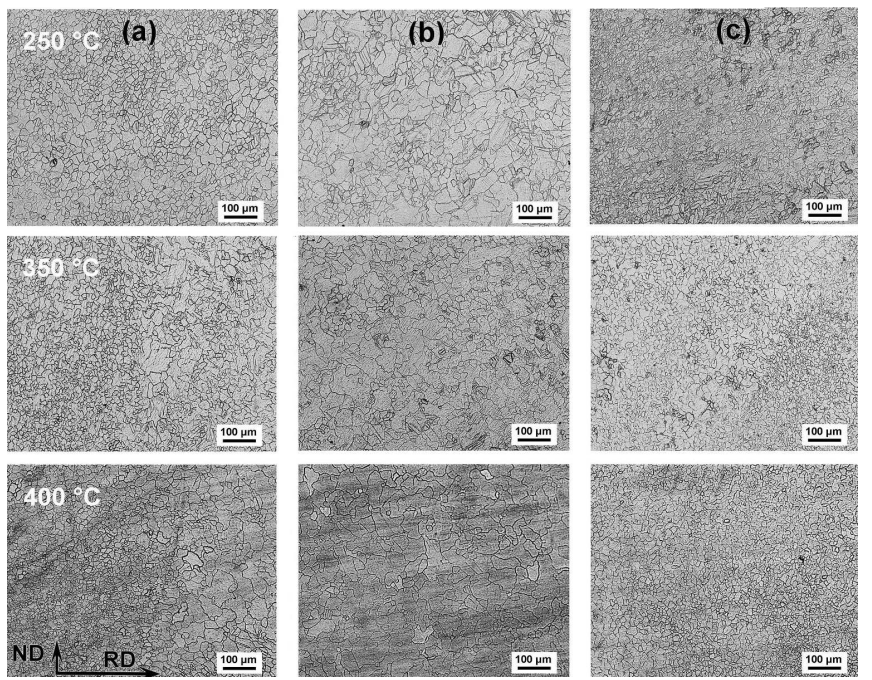

Fig. 4. Microstructure of CGP AZ31 magnesium alloy after annealing at indicated temperatures. Micrographs (a), (b) and (c) correspond to areas similar to ones in Fig. 3(b-d).

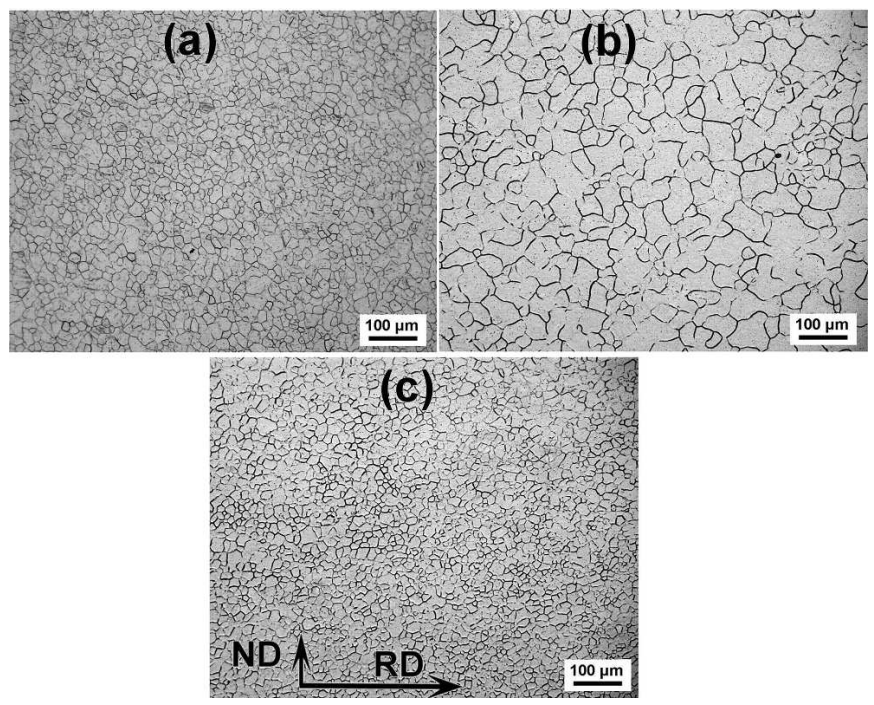

Fig. 5. Microstructure of the material after CGP processing and aging at $450{ }^{\circ} \mathrm{C}$ for $10 \mathrm{~h}$. Micrographs (a), (b) and (c) represent areas marked in white boxes in Fig. 3.

Annealing up to higher temperatures results in the nucleation of new grains and pronounced decrease of the volume fraction of twins. Namely, at $350^{\circ} \mathrm{C}$ and $400{ }^{\circ} \mathrm{C}$ the originally deformed grains are replaced by new finer ones. Their size is around $10 \mu \mathrm{m}$ in the areas (a) and (c) and down to $40 \mu \mathrm{m}$ in the transition area (b). No deformation twins were observed in specimens annealed up to $400^{\circ} \mathrm{C}$.

The long-term high-temperature aging at $450^{\circ} \mathrm{C}$ for $10 \mathrm{~h}$ (Fig. 5) shows that the CGP process promotes uniformity and refinement of the structure. The observed grain size was about $25 \mu \mathrm{m}$ in the transition zones and $\approx 10 \mu \mathrm{m}$ in the rest of the material.

\subsection{Microhardness}

The Vickers microhardness mapping was made at the cross-section in TD of samples. In Fig. 6 changes in the local mechanical properties after CGP are presented. The microhardness distribution also reflects the geometry of the die and is correlated with different observed microstructure. The as-cast material exhibits inhomogeneity mainly in the normal direction (ND) of the strip (Fig. 6a) and higher values of microhardness are generally observed in the center of the strip and near both surfaces, i.e. in areas with significantly finer grains. On the contrary, the CGP material is heterogeneous along the RD (Fig. 6b) and microhardness values reach up to 85 HV0.1 in regions of the highest deformation (regions (b) and (d) in Fig. 3). Similar heterogeneous distribution of local mechanical properties is often observed also in $\mathrm{Al}$ alloys [12].

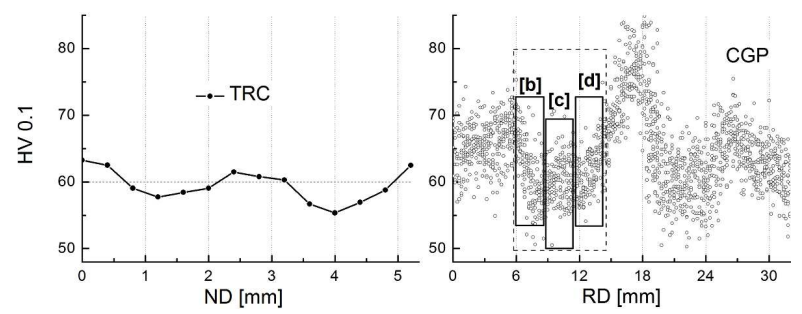

Fig. 6. Vickers microhardness dependence on direction of (a) TRC and (b) CGP specimens; boxes marked by $[\mathrm{b}],[\mathrm{c}]$ and $[\mathrm{d}]$ correspond to the white boxes in Fig. 3 .

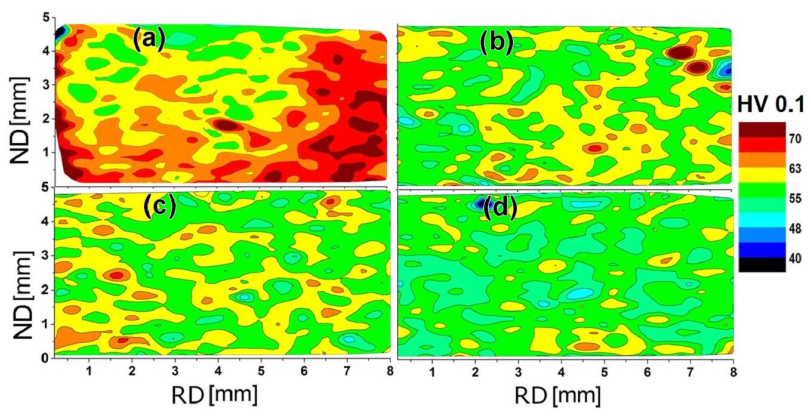

Fig. 7. Vickers microhardness maps of annealed CGP AZ31 magnesium alloy at: (a) $250{ }^{\circ} \mathrm{C}$, (b) $300{ }^{\circ} \mathrm{C}$, (c) $350{ }^{\circ} \mathrm{C}$, (d) $400{ }^{\circ} \mathrm{C}$.

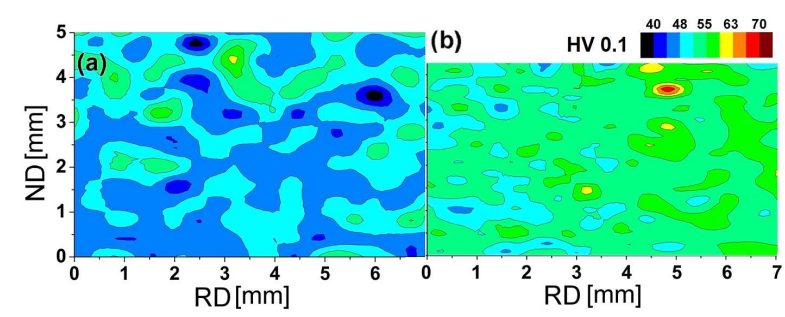

Fig. 8. Vickers microhardness maps of aged (a) TRC and (b) CGP AZ31 magnesium alloy at $450{ }^{\circ} \mathrm{C}$ for $10 \mathrm{~h}$.

The evolution of microhardness during annealing in the CGP material is shown in Fig. 7. For this measurement 
the $8 \times 5 \mathrm{~mm}^{2}$ area containing different types of microstructures and microhardness distribution was chosen (marked by the dashed box in Fig. 6b). Slow softening of the material and elimination of the heterogeneity along the RD occurs with increasing annealing temperature. The microhardness is relatively low and homogeneous after annealing at $400^{\circ} \mathrm{C}$. Microhardness values are comparable with the ones observed in the as-cast material.

Microhardness maps of TRC and CGP plates aged at $450{ }^{\circ} \mathrm{C}$ for $10 \mathrm{~h}$ are given in Fig. 8. Average microhardness of the CGP material is almost 55 HV0.1 while the one for TRC is 45 HV0.1. Thus, thanks to the reduction of the grain size during CGP process a homogeneous material with the microhardness by almost $20 \%$ higher (when compared with the TRC material) without significant dimension reduction can be received.

\section{Summary}

TRC $5.6 \mathrm{~mm}$ thick AZ31 magnesium strip was used as a semiproduct for further mechanical and heat treatment. One CGP cycle was successfully reached by the preheated specimen. The reduction of thickness after CGP was less than $10 \%$. Heterogeneity of the microstructure along the ND of the TRC material (which is common for this technique) is replaced by the heterogeneity along the $\mathrm{RD}$ after one CGP cycle. Nevertheless, elimination of the heterogeneous structure is expected after several CGP cycles.

Due to the imposed deformation during CGP and the grain size decrease, the increase of the microhardness up to $85 \mathrm{HV} 0.1$ occurs. Annealing up to $250^{\circ} \mathrm{C}, 350^{\circ} \mathrm{C}$, and $400^{\circ} \mathrm{C}$ of the CGP material was performed. The recrystallization starting at $350{ }^{\circ} \mathrm{C}$ results in a more uniform grain structure and in the elimination of twins.

After aging at $450{ }^{\circ} \mathrm{C}$ for $10 \mathrm{~h}$ CGP material exhibits almost $20 \%$ higher microhardness values than the aged TRC strip.

\section{Acknowledgments}

This work has been carried out as a part of the project P107-12-0921 of Czech Science Foundation. Authors would like to thank Grant Agency of Charles University in Prague for the financial support under the grant No. 946213. Authors also appreciate the financial support under the grant SVV-2014-260091.

\section{References}

[1] S. Schumann, H.E. Friedrich, S. Durrani, Mater. Sci. Forum 419-422, 51 (2003).

[2] A.A. Luo, A. Luo, T. Shinoda, R.P. Osborne, N. Weaver, Mater. Sci. Forum 419-422, 67 (2003).

[3] M. Avedesian, H. Baker, ASM Specialty Handbook: Magnesium and Magnesium Alloys, ASM International, New York 1999.

[4] H. Zhao, Z. Zhou, X. Liu, S. Guan, J. Cent. South Univ. Technol. 15, 459 (2008).

[5] Z. Shen, A. Ma, J. Jiang, D. Song, F. Lu, M. Noda, K. Funami, Procedia Eng. 27, 475(2012).

[6] G. Kurz, J. Bohlen, L. Stutz, D. Letzig, K.U. Kainer, Mater. Sci. Forum 765, 205 (2013).

[7] D.H. Shin, J.J. Park, Y.S. Kim, K.T. Park, J. Mater Sci. Eng. A 328, 98 (2002).

[8] M. Shantharaja, J. Mater. Sci. Eng. 2, 1 (2013).

[9] P.G. Patridge, Metall. Rev. 12, 169 (1967).

[10] M. Zimina, P. Málek, J. Bohlen, D. Letzig, G. Kurz, M. Cieslar, in: Proc. Int. Conf. Mater. Heat Treat., Czech Republic, 2013, p. 218.

[11] M. Zimina, J. Bohlen, D. Letzig, G. Kurz, M. Cieslar, J. Zník, IOP Conf. Ser. Mater. Sci. Eng. 63, 012078 (2014).

[12] M.S. Ghazani, A. Vajd, Model. Simul. Mater. Sci. Eng. 4, 32 (2014). 